\title{
Influência do manejo do solo na infiltração de água ${ }^{1}$
}

\author{
Influence of soil management on soil infiltration \\ Claudia Klein', Vilson Antonio Klein² \\ ' Doutoranda em Agronomia - Universidade de Passo Fundo (UPF) \\ 2 Engenheiro Agronômo - Universidade de Passo Fundo (UPF)
}

\section{Resumo}

A infiltração de água no solo compreende o processo de entrada de água através da superfície, a água que infiltra é responsável pela recarga de aquíferos. A água armazenada no solo via infiltração é utilizada também pelas plantas, para que estas desempenhem suas funções vitais. Conhecer a taxa de infiltração de água no solo é fundamental para definir técnicas de manejo e conservação do solo, além de auxiliar no planejamento de técnicas de irrigação e drenagem. A infiltração de água é dependente de vários fatores. Neste referencial teórico dar-se-á ênfase no manejo de solo, especialmente em práticas que maximizam a infiltração de água, mitigando a erosão. Dentre as práticas destacamse o mulching vertical, terraceamento, sistema plantio direto e cobertura do solo. A água é um recurso essencial, provavelmente o único recurso natural utilizado em todos os aspectos da civilização, portanto independente do setor é necessária a preservação, e considerando o solo como um filtro universal de alta capacidade de armazenamento é imprescindível que a infiltração seja eficiente.

Palavras-chaves: Mulching vertical, Terraceamento, Sistema plantio direto, Conservação

\begin{abstract}
The soil infiltration is the process of entry of water by surface water that infiltrates is responsible for groundwater recharge. The water stored in the ground via infiltration is also used by plants so that they carry out their vital functions. Knowing the soil infiltration is critical to define management techniques and soil conservation, and assist in planning irrigation and drainage techniques. The soil infiltration is dependent on several factors, this theoretical framework it will focus on soil management, especially in practices that maximize infiltration, reducing erosion. Among the practices stand out from the vertical mulching, terracing, no-tillage and soil cover. Water is an essential resource, probably the only natural resource used in all aspects of civilization, therefore, regardless of the sector is necessary for conservation, and considering soil as a universal filter high storage capacity is essential that the soil infiltration is efficient .
\end{abstract}

Keywords: Vertical mulching, Terracing, No-tillage, Conservation.

1 Revisão de literatura apresentada ao Comitê de Orientação como pré-requisito parcial à obtenção do título de Doutorado em Agronomia. 


\section{INTRODUÇÃO}

Conhecer a taxa de infiltração de água no solo é primordial, por ser uma das características mais sensíveis para detectar alterações no sistema de cultivo e manejo do solo (VILARINHO et al., 2013). Há hipóteses de que as reservas de água não estão sendo recarregadas possivelmente pela infiltração de água ineficiente devido ao manejo inadequado. Frente esta preocupação, o objetivo desta revisão é apresentar estratégias que contribua para aumentar a infiltração de água no solo.

O reabastecimento das reservas de água (aquíferos) depende das condições da preservação ambiental dos locais onde se encontram (DE MORAIS, 2012). Atividades humanas que são exercidas com fins econômicos influenciam de forma direta no processo de infiltração de água no solo e quanto mais próximo das condições naturais estiver o solo, maiores são as taxas de infiltração apresentadas (SILVA, 2012).

A infiltração consiste na entrada de água no solo pela camada superficial, que pela ação da gravidade desce até atingir uma barreira impermeável, formando os lençóis de água. Brandão et al. (2006) salientam que a infiltração é dependente de fatores relacionados ao solo, da superfície, manejo, preparo e das características da própria precipitação. As diferenças na infiltração de água estão relacionadas às frações granulométricas do solo, à quantidade, à espessura, ao ângulo e ao preenchimento das fraturas na camada superficial e às condições de relevo e uso atual do solo (STÜRMER et al., 2009).

Fatores geomorfológicos, especialmente vinculados ao relevo também afetam a dinâmica da infiltração. A forma da encosta (declive) estabelece áreas de convergência e divergência de fluxos (BOTELHO \& SILVA, 2004), instaurando pontos de maior ou menor infiltração (SHOENEBERGER \& WYSOCKI, 2005).

A quantidade e intensidade de insolação recebida tende a influenciar na evaporação e, por conseguinte na infiltração (DE MORAIS, 2012), pois quanto maior a disponibilidade de chuvas (via evaporação), maior a intensidade da precipitação, mais rapidamente o solo atingirá a condição saturada e passará a conduzir água em profundidade, fenômeno denominado condutividade hidráulica do solo.

Santos \& Pereira (2013) evidenciam que a textura e a estrutura são propriedades determinantes na movimentação de água no perfil do solo, uma vez que determinam a quantidade e disposição dos poros. O relevo também pode influenciar esta dinâmica, uma vez que áreas planas tendem a absorver a maior parte da água, e áreas inclinadas tendem a propiciar maior escoamento e baixas taxas de infiltração. A presença de restos culturais, cobertura vegetal é de fundamental importância no processo de percepção da precipitação, evitando o processo de escoamento.

O manejo do solo também tem forte influência na infiltração, geralmente o revolvimento do solo aumenta a entrada de água no perfil devido a maior rugosidade na superfície, menor escoamento. O não revolvimento do solo, no sistema de plantio direto, tende a ocasionar compactação do solo pelo tráfego intensivo de máquinas, o que pode diminuir consideravelmente a infiltração. As taxas de infiltração variam de acordo com o uso do solo (MANCUSO et al., 2014).

Portanto, o escoamento, transporte de sedimentos e o armazenamento de água do solo são fenômenos complexos, que envolvem vários processos interdependentes. Condições antecedentes de umidade, frequência e intensidade de chuvas e a cobertura do solo desempenham um papel importante no processo de infiltração (MONTENEGRO et al., 2013).

Práticas conservacionistas, como o mulching vertical e o terraceamento, vêm sendo utilizadas de forma conjunta com demais técnicas, pois se caracterizam como uma barreira para a água, com vistas a aumentar a infiltração e armazenamento de água e, por conseguinte, reduzir a erosão (DOS SANTOS et al., 2013).

O mulching vertical é baseado no aumento da taxa de infiltração de água no solo, obtida através da construção de sulcos com dimensões de 7,5 a 9,5 cm de largura por $40 \mathrm{~cm}$ de profundidade, dispostos em nível e preenchidos com palha (DENARDIN et al., 2005). Existem também sistemas de mulching que utilizam filmes plásticos biodegradáveis, que são dispostos em uma das paredes do sulco barrando a descida da água.

Garcia \& Righes (2008) observaram que a adoção do mulching vertical em Latossolo distrófico típico sob plantio direto reduz o escoamento em até $48,66 \%$ quando os sulcos foram espaçados em $10 \mathrm{~m}$, e $54,54 \%$ com espaçamento de $5 \mathrm{~m}$, isto é, a água deixa de ser perdida via escoamento para infiltrar no solo.

Nos Estados Unidos, em regiões semi áridas, a produção de milho e batata é realizada utilizando 
a técnica das cristas duplas (terraços) e mulching com filmes plásticos, pois aumentam significativamente a infiltração de água no solo, permitindo o uso eficiente da água pelas plantas que têm ganhos em rendimento (ZHOU et al., 2012; LIU et al., 2014). Li et al. (2013) também sugerem a utilização de mulching com filme plástico biodegradável ou palha para melhorar a disponibilidade de umidade do solo, regular a temperatura e promover o crescimento e produtividade em milho.

O mulching vertical apresenta problemas operacionais, que por vezes inviabiliza a utilização desta técnica. A valetadeira é um implemento que somente abre uma valeta por vez, o que demanda tempo e potência do trator, posteriormente as valetas devem ser preenchidas com palha e resíduos, dependendo do tipo de palha a taxa de mineralização é alta, fazendo com que o sistema tenha pouca vida útil, e por fim, por questões operacionais, há dificuldades de implantar o sistema em áreas com maior declividades.

O terraceamento é uma prática conservacionista de caráter mecânico, cuja implantação envolve a movimentação de terra, por meio de cortes e aterros (CUNHA et al., 2011). A construção é influenciada pelo solo, textura, relevo, cobertura vegetal e tipo de máquina utilizada. A combinação desses fatores é que determina o tipo de terraço a ser utilizado, se a construção for errônea o terraço pode ser ineficiente no armazenamento de água, ocorrendo perdas por escoamento superficial, além de graves problemas de erosão e diminuir a disponibilidade de água para o ecossistema (MAGALHÃES, 2013).

Estudos realizados no Leste da Índia constataram que em terrenos inclinados, os terraços se mostraram úteis na redução do escoamento e na perda de solo, além de ser uma opção promissora para fornecer água às áreas adjacentes (cultivos de hortaliças) funcionando potencialmente como canais escoadouros (PANDA et al., 2011).

No planalto médio do Rio Grande do Sul, a Fazenda Falcão é referência nesta técnica, o sistema foi implantado ainda na década de 1990, uma contravenção à época, mas, esse sistema proporciona benefícios ao solo, como o controle da erosão, incremento nos níveis de nutrientes, maior uso da terra, maiores produtividades, reestruturação do solo, aumento da matéria orgânica, redução da enxurrada, maior infiltração de água no solo (DIÁRIO DA MANHÃ, 2013). O sistema instalado foi projetado fixando o espaçamento horizontal, devido à mecanização, e então se projetou a seção dos terraços utilizando o software Terraços for Windows 4.1 que foi validado e testado por Denardin et al. (1999).

É amplamente reconhecido que o sistema de plantio direto, conserva o solo, economiza energia, melhora o ambiente e a qualidade do solo (KAHLON et al., 2013). O sistema de plantio direto se mostra promissora na melhoria da estrutura do solo, aumentando a infiltração e retenção de água, favorecendo ainda os fluxos ascendentes de água das camadas mais profundas até as camadas mais superficiais, onde se encontra a maior parte do sistema radicular das culturas (FRANCHINI et al., 2009). As taxas de infiltração de água no sistema de plantio direto se mantêm maiores por evitar a formação de crostas superficiais e por aumentar o tempo de oportunidade da infiltração, por causa da maior rugosidade da superfície (LLANILLO et al., 2006). O único empecilho à infiltração no sistema de plantio direto é quando há compactação do solo e assim ocorre decréscimo na taxa de infiltração básica.

Cássaro et al. (2011) avaliaram as modificações do diâmetro dos poros de um Latossolo Vermelho submetido ao sistema de plantio direto e plantio convencional por longo prazo, e evidenciaram que o não revolvimento do solo promoveu aumento da microporosidade do solo (poros de água disponível às plantas) em comparação ao outro tratamento.

Dalmago et al. (2009) observaram que a retenção de água em solo (Argissolo Vermelho) sob sistema de plantio direto é maior do que no preparo convencional, especialmente nas camadas superficiais, bem como a disponibilidade de água as plantas. A distribuição decrescente dos mesoporos no solo em plantio direto com maior frequência em diâmetros maiores determina menor energia de retenção da água disponível às plantas que no solo em preparo convencional, cuja mesoporosidade segue uma curva de distribuição normal.

Lanzanova et al. (2010) avaliaram atributos físicos de um Argissolo em sistemas de culturas de longa duração (16 anos) sob sistema de plantio direto, sendo os sistemas: a) milho + feijão-de-porco/ soja; b) solo descoberto, c) milho/ pousio/ soja; d) milho/ azevém+ ervilhaca-comum/ soja; e) milho+ mucuna-cinza/soja; f) milho/ nabo forrageiro/ soja, e g) campo nativo e verificaram que as menores taxas de infiltração de água no solo foram nos tratamentos solo descoberto e campo nativo, enquanto os demais se mantiveram constantemente acima destes e semelhantes entre si. O sistema de plantio direto com uso de plantas de cobertura do solo mostrou-se eficiente em manter atributos físicos, ao 
mesmo tempo em que melhorou atributos como a taxa de infiltração de água.

A técnica que utiliza esporadicamente escarificadores para mobilizar o solo em áreas sob sistema de plantio direto é comumente designada de plantio direto escarificado, e proporciona os maiores valores de retenção de água em superfície, principalmente em função do aumento da porosidade e infiltração eficaz neste sistema (CASTRO et al., 2010). Constata-se alterações na distribuição do volume dos poros no solo, Klein (2011) observou aumento de microporos em Latossolo Vermelho com escarificação, em relação ao sistema de plantio direto, o que proporcionou maior lâmina de água armazenada em profundidade.

O aumento dos macroporos em sistema de plantio direto também é importante para a conservação do solo e da água, pois está diretamente relacionado com a melhoria da aeração e infiltração de água no solo (SCHIAVO \& COLODRO, 2012) e este aumento nos macroporos pode ser obtido pela escarificação eventual (KLEIN et al., 2008; SILVA JÚNIOR et al., 2010).

Girardello et al. (2011) testaram diferentes escarificadores e obtiveram aumento na infiltração de água no solo quatro vezes superior que na área não escarificada, porém constataram que este efeito foi temporário, prevalecendo por apenas sete meses após o preparo.

O manejo do solo com escarificação proporciona maior infiltração de água no solo apenas no primeiro ano. Esta constatação foi observada por Prando et al. (2010), avaliando a infiltração de água em um Nitossolo Vermelho distrófico, com três sistemas de rotação de culturas sob semeadura direta, com e sem escarificação inicial. O sistema de rotação de culturas constou de: a) milheto/ soja/ sorgo/ milho/ sorgo, b) milheto/ soja/ Brachiaria ruziziensis/ milho/ brachiaria e c) milheto/soja/ brachiaria+mamona/ milho/ brachiaria+mamona, constataram ainda que a atividade do sistema radicular das espécies nas parcelas sem escarificação aumentou a velocidade de infiltração da água no solo e que independentemente do solo escarificado ou não, a rotação de culturas envolvendo Brachiaria ruziziensis + mamona resultou em maior infiltração de água no solo.

Mazurana et al. (2011) analisaram a implicação que diferentes sistemas de preparo de solo impõem sobre a infiltração em Argissolo Vermelho, inicialmente sob uso com campo natural. Cinco métodos de preparo de solo foram testados: semeadura direta, escarificação, semeadura direta com escarificação a cada dois anos, escarificação com escarificador munido de rolo destorroador e escarificação seguida de gradagem. A taxa de infiltração de água foi superior no sistema escarificador com rolo destorroador+gradagem, seguido pelos sistemas de escarificação, semeadura direta e semeadura direta+escarificação.

A escarificação mecânica como método isolado de descompactação não favoreceu a infiltração de água no solo, no entanto, o uso do consórcio de nabo-forrageiro e aveia-preta em sistema de plantio direto, ou após a escarificação mecânica do solo, aumentou significativamente a lâmina de água infiltrada no solo, estas constatações foram feitas em estudo que avaliou a eficiência do método mecânico (escarificador) e do método biológico (nabo-forrageiro) de descompactação do solo (NICOLOSO et al., 2008). O maior rendimento de grãos de soja foi observado no tratamento ESC-Nb+Av $(3,73 \mathrm{Mg}$ $\left.\mathrm{ha}^{-1}\right)$, que não diferiu significativamente do SD-Nb+Av $\left(3,49 \mathrm{Mg} \mathrm{ha}^{-1}\right)$.

Cabe ressaltar que a escarificação mecânica é uma operação de elevada demanda de potência, alto consumo de combustível e de tempo, portanto, preferencialmente, deveria ser aplicada somente onde a compactação é severa (GIRARDELLO et al., 2011) e constatada através de análises físicas do solo.

O sistema Guimarães Duque é uma técnica de preparo do solo, associada à captação da água da chuva em sulcos construídos em curva de nível, fechados e nivelados, que resulta na retenção da umidade no perfil do solo por um período mais longo, beneficiando as plantas (OLIVEIRA et al., 2010). Este método geralmente produz escoamento superficial, pois, para construí-lo utiliza-se arado e quando chove pouco a rugosidade do sistema retém a água nos sulcos, porém quando há precipitações de maior volume, água e solo são perdidos.

As características da vegetação influenciam a dinâmica da água, podem reduzir a evaporação, aumentar a capacidade de infiltração e proteção do solo contra os efeitos danosos provocados pelo impacto das gotas de chuva, evitam o carregamento e sedimentação de partículas nas partes mais baixas do terreno, principalmente para os cursos de água alterando sua qualidade (DA SILVA et al., 2007).

As características das espécies vegetais, como o tipo de raiz e de folha, o ângulo de disposição das folhas em relação ao colmo, a quantidade e espessura dos colmos e o hábito de crescimento das plantas, influenciam na dinâmica da água no solo. As raízes, por exemplo, apodrecem formando canais, que auxiliarão na condução da água em profundidade. Folhas mais eretas captam mais água, 
conduzindo em direção ao colmo/tronco fornecendo água na zona radical.

Da mesma forma, o nabo forrageiro é recomendado para descompactar (desde que semeado em altas densidades) e melhorar a estrutura do solo. Devido seu sistema radicular característico, essa crucífera proporciona aumentos na porosidade do solo, favorecendo a infiltração de água (PITOL \& SALTON, 1993). Já a aveia por ter elevada produção de palhada protege o solo devido a seu denso e fasciculado sistema radicular promove a eliminação de crostas do solo, formando agregados, melhorando a estrutura do solo, tornando-o mais poroso e arejado. Com isso, dá-se maior infiltração e armazenamento de água no perfil do solo (HERNANI et al., 1995).

Nicoloso et al. (2008) consorciaram nabo forrageiro + aveia preta para descompactação biológica do solo, e observaram que o sistema foi eficiente para aumentar a macroporosidade e a infiltração de água no solo.

Zaluski \& Antonelli (2014) avaliaram a infiltração de água em áreas com cultivo de tabaco e observaram que a infiltração média das entrelinhas ao longo do cultivo foi de $25,6 \mathrm{~mm} \mathrm{~h}^{-1}$, enquanto que nos camalhões foi de $40,9 \mathrm{~mm} \mathrm{~h}^{-1}$. Esta variação pode estar associada ao manejo do solo em ambas as áreas, a influência da morfologia da planta do tabaco que potencializa a cobertura do solo nos camalhões e a compactação do solo.

A distribuição de resíduos de culturas no solo é uma prática comum para o controle da erosão do solo e para a melhoria da infiltração de chuvas (MONTENEGRO et al., 2013). A cobertura morta a partir de resíduos de cultivos protege a superfície do solo, reduzindo o processo de ressecamento e escoamento. A cobertura reduz a velocidade do vento sobre o terreno em até $99 \%$ e, por isso, a perda de água por evaporação é reduzida. Ademais, cultivos de cobertura e resíduos de plantas espontâneas podem melhorar a penetração de água e diminuir de duas e seis vezes as perdas em função do escoamento (NICHOLLS \& ALTIERI, 2012).

Ensaios realizados na região árida da China, com manutenção de resíduos de milho sobre a superfície e com incorporação de parte desta $\left(12 \mathrm{Mg} \mathrm{ha}^{-1}\right)$ na profundidade de $0-40 \mathrm{~cm}$, por três anos, consecutivos, aumentaram a umidade no perfil do solo (ZHAO et al., 2014). O uso de cobertura morta no solo é uma prática recomendada, especialmente em regiões semi áridas, contribuindo para a melhoria do desempenho das culturas, redução das perdas de água do solo e da erosão superficial (SOUZA et al., 2008).

Um estudo avaliou as perdas de água e estimou a taxa de infiltração estável de água no solo em diferentes sistemas de manejo (semeadura direta, preparo com grade aradora e com escarificador), sob chuva simulada $\left(60 \mathrm{~mm} \mathrm{~h}^{-1}\right)$, associados a três níveis de cobertura do solo com resíduo vegetal: 0,0 ; 2,0; e 4,0 $\mathrm{Mg} \mathrm{ha}^{-1}$, após a colheita da cultura da soja. As perdas de água variaram de 1,60 a 106,94 $\mathrm{m}^{3}$ $\mathrm{ha}^{-1} \mathrm{~h}^{-1}$. A taxa de infiltração estável de água apresentou variação entre 23 e $52 \mathrm{~mm} \mathrm{~h}^{-1}$. Os tratamentos sob semeadura direta sem cobertura do solo e sob preparo com grade aradora apresentaram maiores perdas de solo e de água, e valores mais baixos de taxa de infiltração estável de água (PANACHUKI et al., 2011)

Alguns estudos divergem quanto a influência dos resíduos/coberturas na infiltração de água, perdas de solo e água por erosão hídrica entre sulcos de um Argissolo Vermelho-Amarelo, utilizando chuva simulada e diferentes densidades de cobertura vegetal de 0,2 e $4 \mathrm{Mg} \mathrm{ha}^{-1}$. As perdas foram quantificadas durante 90 minutos de chuva, com intensidade de $100 \mathrm{~mm} \mathrm{~h}^{-1}$. O tratamento sem cobertura vegetal apresentou maiores taxas de desagregação do solo quando comparado aos tratamentos com 2 e $4 \mathrm{Mg} \mathrm{ha}^{-1}$. A utilização de cobertura vegetal reduziu a taxa de desagregação do solo, no entanto não influenciou nas perdas de água e na taxa de infiltração da água no solo (TARTARI et al., 2012).

O revolvimento na linha de semeadura, por ocasião da semeadura, também se mostra importante, já que cria microrrelevo propício à infiltração. Klein (2011), constatou que o solo na linha de semeadura tolera mais a variação de umidade em relação à entrelinha permanecendo por mais tempo dentro da faixa de umidade ótima, isso em cultivo de milho, onde a arquitetura da planta induz a destinação da precipitação ao colmo e, posteriormente, ao solo, próximo às raízes, desde que a infiltração seja eficiente.

O microrrelevo superficial é influenciado pelo preparo do solo (CASTRO et al., 2006), que afeta os poros nesta camada e que, com a cobertura por resíduos vegetais, influencia a armazenagem de água, a infiltração de água no solo (DARBOUX \& HUANG, 2005). O microrrelevo depende do tipo e da intensidade de preparo, e do teor de água do solo precedente, da quantidade, tipo e manejo de resíduo vegetal sobre o solo, e do tipo de solo (CASTRO et al., 2006). 
A operação de semeadura (especialmente a direção) influencia a rugosidade da superfície do solo (LUCIANO et al., 2009), portanto, ao realizar a mesma ocorrerá a formação de micro terraços que auxiliarão na retenção de água sobre o terreno e posterior infiltração.

Outros sistemas são conhecidos e difundidos nas regiões áridas do Brasil, são antigos, porém carecem estudos científicos, tais como: Sistema W ou camalhões inclinados; o sulcamento pré e pós -plantio, que consiste na realização da aração do solo formando camalhões para o cultivo; plantio em covas, ou coroamento (espécies frutíferas) onde com o auxilio de uma enxada, faz-se uma pequena depressão capaz de armazenar água da chuva; sulcos barrados, também realizadas com arados, onde se abre o sulco e posteriormente levanta-se no meio destas pequenas barreiras, com intuito de evitar o escoamento e por fim a aração parcial, que consiste na aração de faixas da área de lavoura, todas técnicas que visam potencializar a infiltração de água no solo.

Brito et al. (2008) avaliaram cinco sistemas de manejo do solo, sendo eles: Guimarães Duque, aração profunda, aração parcial, sulcos barrados e sistema tradicional (plano), monitoraram a umidade do solo durante todo o ciclo da cultura do milho e constataram maiores umidades no manejo sulcos barrados.

A matéria orgânica é um constituinte do solo que permite maior agregação e coesão entre as partículas, tornando o solo mais poroso e com maior retenção de água, beneficiando a infiltração (SPERA et al., 2010; SANTOS \& PEREIRA, 2013). Karami et al. (2012), avaliando os efeitos de diferentes fontes (esterco de ovelha, estrume de vaca, casca de arroz, cana picada, palha de trigo, alcaçuz-raiz) e quantidades de matéria orgânica $\left(5,15\right.$ e $\left.25 \mathrm{Mg} \mathrm{ha}^{-1}\right)$, observaram que, independente da fonte e da quantidade aplicada, houve aumento na taxa de infiltração.

Mellek et al. (2010) avaliaram as contribuições de esterco líquido sobre a qualidade hidráulica de um Cambissolo sob plantio direto. O esterco líquido foi aplicado durante dois anos, em doses de $0,60,120$ e $180 \mathrm{~m}^{3} \mathrm{ha}^{-1}$ ano $^{-1}$, e constataram que na camada de $0-5 \mathrm{~cm}$ (dose 180) a condutividade hidráulica saturada aumentou quase cinco vezes, comparada ao solo controle, ou seja, ocorreu aumento na infiltração de água no solo.

A aplicação de resíduos orgânicos ou provenientes de descartes de indústrias tem sido comum em solos agrícolas, e esta técnica pode ter implicação na infiltração. Dalri et al. (2010) verificaram que a aplicação de vinhaça em solo franco arenoso propiciou redução da taxa de infiltração básica, especialmente pela formação de crostas sobre a superfície do solo.

Em sistemas de integração lavoura-pecuária, o impacto causado pelo pisoteio bovino sobre o solo têm reflexos nos atributos físicos. Lanzanova et al. (2007) observaram que a taxa de infiltração de água no solo foi alterada pelo pisoteio bovino e pela cultura de verão antecedente. Com a cultura de milho, o solo mostrou-se menos sensível ao pisoteio bovino, ao passo que com a cultura de soja na maior frequência de pastejo (a cada 14 dias) a taxa de infiltração de água no solo foi reduzida.

Miguel et al. (2009) verificaram que quinze passagens do gado pelos piquetes resultaram em diminuição da taxa de infiltração de água no solo de 73,3\%, a 0,10 m, e de 64,6\% a 0,20 m de profundidade, com taxa de lotação média de seis unidade animal ha ano ${ }^{-1}$, período de ocupação de seis dias e descanso de 30 dias.

No Bioma Cerrado, as atividades agrícolas têm provocado impactos negativos, principalmente, na qualidade do solo e da água, os usos do solo com sistema de lavoura contínua, pecuária contínua e integração lavoura-pecuária tiveram a velocidade de infiltração básica e infiltração acumulada reduzidas em relação ao solo com vegetação nativa (BONO et al., 2012).

A literatura sugere que o pisoteio pelo gado aumenta a densidade do solo e reduz a macroporosidade e a taxa de infiltração. No entanto, os efeitos estão concentrados à superfície do solo (0-0,1 $\mathrm{m}$ ) e são de curta duração, devido à melhoria através de processos naturais ou de cultivo. Além disso, esses riscos podem ser minimizados, evitando pastoreio excessivo durante condições de alta umidade e manutenção de cobertura vegetal adequada (BELL et al., 2011).

O uso de pastagens tem assumido importância em áreas de desertificação. Os sistemas de pastagens/pecuária à longo prazo pode resultar em aumento da infiltração de água que está associado com reduções na compactação do solo devido a abundância de resíduos das pastagens (CASTELLANO \& VALONE, 2007).

O tráfego controlado tem sido sugerido como uma forma de melhorar a infiltração de água e reduzir as perdas de solo em culturas anuais irrigadas em ambientes (BOULAL et al., 2011), mas pouca pesquisa é disponível. 
Por fim, ressalta-se a recente e inovadora política pública "Programa Produtor de Água" que apesar de considerar de forma explícita, apenas o abatimento relativo à erosão do solo, há uma correlação óbvia entre este e o aumento da infiltração de água no solo, o que irá contribuir para a recarga dos aquíferos e a maior disponibilidade de água durante as estações secas (SANTOS et al., 2010).

A água é um recurso essencial, finito, e é utilizada por todos os organismos vivos e setores da sociedade, portanto é primordial preservá-la. O solo é um filtro universal e totalmente natural, deste modo práticas de manejo de solo são de simples realização e indispensáveis à infiltração, armazenamento e qualidade da água. Em síntese, uma técnica sozinha não potencializará a infiltração, mas o uso conjunto das técnicas que se adaptam a realidade da propriedade agrícola em questão.

\section{CONSIDERAÇÕES}

A otimização da infiltração de água no solo é fundamental. Dentre as técnicas apresentadas a magnificência só será alcançada se forem utilizadas de forma integrada, e a escolha dependerá de diversos fatores, clima, relevo, cultura, disponibilidade financeira, entre outras. A água é um recurso finito e deve ser preocupação de todos os âmbitos da sociedade, o ponto primordial o uso consciente.

\section{REFERÊNCIAS}

BELL, L. W.; KIRKEGAARD, J. A.; SWAN, A.; HUNT, J. R.; HUTH, N. I.; FETTELL, N. A. Impacts of soil damage by grazing livestock on crop productivity. Soil \& Tillage Research, Amsterdam, v. 113, n.1, p. 19-29, maio, 2011.

BONO, J. A. M.; MACEDO, M. C. M.; TORMENA, C. A.; NANNI, M. R.; GOMES, E. P.; MÜLLER, M. M. L. Infiltração de água no solo em um Latossolo Vermelho da região sudoeste dos Cerrados com diferentes sistemas de uso e manejo. Revista Brasileira de Ciência do Solo, Viçosa, v. 36, n. 6, 2012.

BOTELHO, R. G. M.; SILVA, A. S. Bacia hidrográfica e qualidade ambiental. In: VITTE, A. C.; GUERRA, A. J. T. (Orgs.) Reflexões sobre geografia física no Brasil. Rio de Janeiro, Bertrand, p. 153-192, 2004.

BOULAL, H.; GÓMEZ-MACHPHERSON, H.; GÓMEZ, J. A.; MATEOS, L. Effect of soil management and traffic on soil erosion in irrigated annual crops. Soil \& Tillage Research, Amsterdam, v. 115-116, p. 62-70, out/nov, 2011.

BRANDÃO, V. S.; CECÍLIO, R. A.; PRUSKI, F. F.; SILVA, D. D. Infiltração de água no solo. Editora UFV, Viçosa, 2006. 120p.

BRITO, L. T. L.; CAVALCANTI, N. B.; ANJOS, J. B.; SILVA, A. S.; PEREIRA, L. A. Perdas de solo e de água em diferentes sistemas de captação in situ no semi-árido brasileiro. Engenharia Agrícola, Jaboticabal, v. 28 , n. 3, p. 507-515, set, 2008.

CÁSSARO, F. A. M., BORKOWSKI, A. K.; PIRES, L. F.; ROSA, J. A.; SAAB, S. C. Characterization of a Brazilian clayey soil submitted to conventional and no-tillage management practices using pore size distribution analysis. Soil \& Tillage Research, Amsterdam, v. 111, n.2, p. 175-179, jan, 2011.

CASTELLANO, M. J.; VALONE, T. J. Livestock, soil compaction and water in $\square$ ltration rate: Evaluating a potential deserti $\square$ cation recovery mechanism. Journal of Arid Environments, [S.1.], v. 71, n.1, p. 97-108, out, 2007.

CASTRO, L. G.; COGO, N. P.; VOLK, L. B. S. Alterações na rugosidade superficial do solo pelo preparo e pela chuva e sua relação com a erosão hídrica. Revista Brasileira de Ciência do Solo, Viçosa, v. 30, n. 2, p. 339-352, 2006. 
CASTRO, O. M.; VIEIRA, S. R.; SIQUEIRA, G. M. Atributos físico-hídricos de um Latossolo Vermelho eutroférrico sob diferentes sistemas de manejo. Bragantia, Campinas, v. 69, n. 2, p. 433-443, 2010.

CUNHA, F. F.; LEAL, A. J. F; ROQUE, C. G. Planejamento de sistemas de terraceamento utilizando o software Terraço 3.0. Brazilian Geographical Journal: Geosciences and Humanities research medium, Ituiutaba, v. 2, n. 1, p. 182-196, 2011.

DA SILVA, M. A. S.; GRIEBELER, N. P.; BORGES, L. C. Uso de vinhaça e impactos nas propriedades do solo e lençol freático. Revista Brasileira de Engenharia Agrícola e Ambiental, Campina Grande, v. 11, n. 1, p. 108-114, 2007.

DALMAGO, G. A.; BERGAMASCHI, H.; BERGONCI, J. I.; KRUGER, C. A. M.; COMIRAN, F.; HECKLER, B. M. M. Retenção e disponibilidade de água às plantas, em solo sob plantio direto e preparo convencional. Revista Brasileira de Engenharia Agrícola e Ambiental, Campina Grande, v. 13 (suplemento), p. 855-864, 2009.

DALRI, A. B.; CORTEZ, G. E. P.; RIUL, L. G. S.; ARAÚJO, J. A. C.; CRUZ, R. L. Influência da aplicação de vinhaça na capacidade de infiltração de um solo de textura franco arenosa. Irriga, Botucatu, v. 15, n. 4, p. 344-352, 2010.

DARBOUX, F.; HUANG, C. Does soil surface roughness increase or decrease water and particle transfers? Soil Science Society of America Journal, Madison, v. 69, n. 3, p. 748-756, maio, 2005.

DE MORAIS, F. Infiltração - uma variável geomorfológica. Cadernos de Geografia, Belo Horizonte, v. 22, n. 38, jul/dez, 2012.

DENARDIN, J. E.; KOCHHANN, R. A.; BERTON, A.; TROMBETTA, A.; FALCÃO, H. Terraceamento em plantio direto. Comunicado técnico online, Embrapa Trigo, Passo Fundo, no 8, fev 1999. 4 p.

DENARDIN, J. E.; KOCHHANN, R. A.; RIGHES, A. A. Mulching Vertical: técnica de manejo de enxurradas em Sistema Plantio Direto. Revista Plantio Direto, Passo Fundo, v. 85, 2005.

DIÁRIO DA MANHÃ. A importância da Conservação do Sistema, Passo Fundo, 2013. Disponível em: http://www.miti.com.br/ce2//?a=noticia\&nv=QsrXAm92cjqv O1IUt5alsEmUFS_D8ixL. Acesso em 03 de junho de 2014.

DOS SANTOS, R. C.; SOUZA, C. M.; REZENDE, M. J.; LANI, J. L.; CECON, P. R.; GOMES, M. A. Proposta metodológica para o cálculo de espaçamento entre sulcos de mulching vertical. Revista Ceres, Viçosa, v. 60, n. 4, p. 552-562, jul/ago, 2013.

FRANCHINI, I. C.; DEBIAIS, H.; SACOMAN, A.; NEPOMUCENO, A. L.; FARIAS, J. R. B. Manejo do solo para redução das perdas de produtividade pela seca. Documentos, Embrapa Soja, Londrina, 2009.

GARCIA, S. M.; RIGHES, A. A. Vertical Mulching e manejo da água em semeadura direta. Revista Brasileira de Ciência do Solo, Viçosa, v. 32 n. 2, p. 833-842, 2008.

GIRARDELLO, V. C.; AMADO, T. J. C.; NICOLOSO, R. S.; HORBE, T. A. N.; FERREIRA, A. O.; TABALDI, F. M.; LANZANOVA, M. E. Alterações nos atributos físicos de um Latossolo Vermelho sob plantio direto induzidas por diferentes tipos de escarificadores e o rendimento da soja. Revista Brasileira de Ciência do Solo, Viçosa, v. 35, n.6, p. 2115-2126, 2011.

HERNANI, L. C.; ENDRES, V. C.; PITOL, C.; SALTON, J. C. Adubos verdes de outono/inverno no Mato Grosso do Sul. Ministério da Agricultura, do Abastecimento e da Reforma Agrária. Embrapa. Centro de Pesquisa Agropecuária do Oeste, Dourados, 1995. 
KAHLON, M. S.; LAL, R.; ANN-VARUGHESE, M. Twenty two years of tillage and mulching impacts on soil physical characteristics and carbon sequestration in Central Ohio. Soil \& Tillage Research, Amsterdam, v. 126, p. 151-158, jan, 2013.

KARAMI, A.; HOMAEE, M.; AFZALINIA, S.; RUHIPOUR, H.; BASIRAT, S. Organic resource management: Impacts on soil aggregate stability and other soil physico-chemical properties. Agriculture, Ecosystems and Environment, [S.1.], v. 148, p. 22-28, fev, 2012.

KLEIN, C. Propriedades físico-hídrico-mecânicas e rendimento de grãos de milho em Latossolo vermelho sob plantio direto escarificado. 2011, Dissertação de mestrado em Produção Vegetal, Universidade de Passo Fundo, Passo Fundo, 2011.

KLEIN, V. A.; VIEIRA, M. L.; DURIGON, F. F.; MASSING, J. P.; FÁVERO, F. Porosidade de aeração de um Latossolo e rendimento de Trigo em plantio direto escarificado. Ciência Rural, Santa Maria, v. 38, n. 2, p. 265-371, mar-abr, 2008.

LANZANOVA, M. E.; NICOLOSO, R. S.; LOVATO, T.; ELTZ, F. L. F.; AMADO, T. J. C.; REINERT, D .J. Atributos físicos do solo em sistema de integração lavoura-pecuária sob plantio direto. Revista Brasileira de Ciência do Solo, Viçosa, v. 31, n.4, p. 1131-1140, 2007.

LANZANOVA, M. E.; ELTZ, F. L. F.; NICOLOSO, R. S.; AMADO, T. F. C.; REINERT, D. J.; ROCHA, M. R. Atributos físicos de um Argissolo em sistemas de culturas de longa duração sob semeadura direta. Revista Brasileira de Ciência do Solo, Viçosa, v. 34, n.5, p. 1333-1342, 2010.

LI, R.; XIANGING, H.; ZHIKUAN, J.; QINGFANG, H.; XIAOLONG, R.; BAOPING, Y. Effects on soil temperature, moisture, and maize yield of cultivation with ridgeand furrow mulching in the rainfed area of the Loess Plateau, China. Agricultural Water Management. [S.1.], v. 116, p. 101-109, jan, 2013.

LIU, C.; ZHOU, L; JIA, J.; SI, J.; LI, X.; PAN, C.; SIDDIQUE, K. H.; LI, F. Maize yield and water balance is affected by nitrogen application in a film-mulching ridge-furrow system in a semiarid region of China. European Journal of Agronomy. [S.1.], v. 52, p. 103-111, 2014.

LLANILLO, R. F.; RICHART, A.; FILHO, J. T.; GUIMARÃES, M. F.; FERREIRA, R. R. M. Evolução de propriedades físicas do solo em função dos sistemas de manejo em culturas anuais. Semina: Ciências Agrárias, Londrina, v. 27, n. 2, p. 205-220, abr/jun, 2006.

LUCIANO, R. V.; BERTOL, I.; BARBOSA, F. T.; VIDAL VÁZQUEZ, E.; FABIAN, E. L. Perdas de água e solo por erosão hídrica em duas direções de semeadura de aveia e ervilhaca. Revista Brasileira de Ciência do Solo, Viçosa, v. 33, p. 669-676, 2009.

MAGALHÃES, G. M. F. Análise da eficiência de terraços de retenção em sub-bacias hidrográficas do Rio São Francisco. Revista Brasileira de Engenharia Agrícola e Ambiental. Campina Grande, v. 17, n. 10, p. 1109-1115, out, 2013.

MANCUSO, M. A.; FLORES, B. A.; ROSA, G. M. SCHROEDER, J. K.; PRETTO, P. R. P. Características da taxa de infiltração e densidade do solo em distintos tipos de cobertura de solo em zona urbana. Revista Monografias Ambientais, Santa Maria, v. 14, n.1, Edição Especial p. 2890-2998, fev, 2014.

MAZURANA, M.; LEVIEN, R.; MULLER, J.; CONTE, O. Sistemas de preparo de solo: alterações na estrutura do solo e rendimento das culturas. Revista Brasileira de Ciência do Solo, Viçosa, v. 35, n. 4, 2011.

MELLEK, J. E.; DIECKOW, J.; SILVA, V. L.; FAVARETTO, N.; PAULETTI, V.; VEZZZANI, F. M.; SOUZA, J. L. M. Dairy liquid manure and no-tillage: Physical and hydraulic properties and carbon stocks in a Cambisol of Southern Brazil. Soil \& Tillage Research, Amsterdam, v. 110, p. 69-76, 2010. 
MIGUEL, F. R. M.; VIEIRA, S. R.; GREGO, C. R. Variabilidade espacial da infiltração de água em solo sob pastagem em função da intensidade de pisoteio. Pesquisa Agropecuária Brasileira, Brasília, v. 44, n. 11, p. 1513-1519, nov, 2009.

MONTENEGRO, A. A. A.; ABRANTES, J. R. C. B.; LIMA, J. L. M. P.; SINHGH, V. P.; SANTOS, T. E. M. Impact of mulching on soil and water dynamics under intermittent simulated rainfall. Catena, Amsterdam, v. 109, p. 139-149, 2013.

NICHOLLS, C. I.; ALTIERI, M. A. Estratégias agroecológicas para aumentar a resiliência no contexto das mudanças climáticas. Agriculturas: experiências em agroecologia, Cruz Alta, v. 9, n. 1, 2012.

NICOLOSO, R. S.; AMADO, T. J. C.; SCHNEIDER, S.; LANZANOVA, M. E.; GIRARDELLO, V. C.; BRAGAGNOLO, J. Eficiência da escarificação mecânica e biológica na melhoria dos atributos físicos de um Latossolo muito argiloso e no incremento do rendimento de soja. Revista Brasileira de Ciência do Solo, Viçosa, v. 32, p. 1723-1734, 2008.

OLIVEIRA, J. B.; ALVES, J. J.; FRANÇA, F. M. C. Práticas de manejo e conservação de solo e água no semiárido do Ceará. Secretaria dos Recursos Hídricos, Fortaleza, 2010.

PANACHUKI, E.; BERTOL, I.; ALVES SOBRINHO, T.; OLIVEIRA, P. T. S.; RODRIGUES, D. B. B. Perdas de solo e de água e infiltração de água em Latossolo Vermelho sob sistemas de manejo. Revista Brasileira de Ciência do Solo, Viçosa, v. 35, p. 1777-1785, 2011.

PANDA, R. K.; ARORA, C. P.; GORE, K. P.; JAKHAR, P.; DASH, B. K. Managing terraced lowland and medium sloping land for sustainable agriculture: a study from the eastern ghat region of India. Irrigation and Drainage, [S.1.], v. 60, p. 694-702, 2011.

PITOL, C.; SALTON, J. C. Nabo forrageiro: opção para cobertura de solo. Fundação MS para Pesquisa e Difusão de Tecnologias Agropecuárias, 1993. 4p.

PRANDO, M. B.; OLIBONE, D.; OLIBONE, A. P. E.; ROSOLEM, C. A. Infiltração de água no solo sob escarificação e rotação de culturas. Revista Brasileira de Ciência do Solo, Viçosa, v. 34, p. 693-700, 2010.

SANTOS et al., Gestão de recursos hídricos na agricultura: O programa produtor de água. In: PRADO, R. B. et al., (2010) Manejo e Conservação do solo e da água no contexto das mudanças climáticas. Embrapa Solos. 2010.

SANTOS, J. N.; PEREIRA, E. D. Carta de susceptibilidade a infiltração da água no solo na sub-bacia do rio Maracanã-MA. Cadernos de Pesquisa, São Luís, v. 20, n. especial, julho 2013.

SCHIAVO, J. A.; COLODRO, G. Agregação e resistência à penetração de um Latossolo Vermelho sob sistema de integração. Bragantia, Campinas, v. 71, n. 3, p. 406-412, 2012.

SCHOENEBERGER, P. J.; WYSOCKI, D. A. Hydrology of soils and deep regolith: a nexus between soil geography, ecosystems and land management. Geoderma, Amstedam, v. 126, p. 117-128, 2005.

SILVA JUNIOR, C. A.; CARVALGO, L. A.; MEURER, I.; LIBARDI, P. L.; SILVA, M. A. C.; OLIVEIRA, E. C. A. Alterações nos atributos físicos de um Latossolo Vermelho sob diferentes métodos de preparo para o plantio da cana-de-açúcar. Revista Agrarian, Dourados, v. 3, n. 8, p. 111-118, 2010.

SILVA, I. C. da. Estudo da capacidade de infiltração de água diante de diferentes usos do solo no município de Itapororoca/PB. Revista Geonorte, Edição Especial, Amazonas, v. 1, n. 4, p. 648 - 662, 2012.

SOUZA; E. R.; MONTENEGRO, A. A. A.; MONTENEGRO, S. M. G. L. Variabilidade espacial da umidade do solo em Neossolo Flúvico. Revista Brasileira de Recursos Hídricos, Porto Alegre, v. 13, n. 2, p. 177-187, 
2008.

SPERA, S.; SANTOS, H. P.; FONTANELI, R. S.; TOMM, G. O. Atributos físicos de um Hapludox em função de sistemas de produção integração lavoura- produção integração lavoura---pecuária (ILP), sob plantio direto pecuária (ILP), sob plantio direto pecuária (ILP), sob plantio direto. Acta Scientiarum Agronomy, Maringá, v. 32, n. 1, p. 37-44, 2010.

STÜRMER, S. L. K.; DALMOLIN, R. S. D.; AZEVEDO, A. C.; PEDRON, F. A.; MENEZES, F. P. Relação da granulometria do solo e morfologia do saprolito com a infiltração de água em Neossolos Regolíticos do rebordo do Planalto do Rio Grande do Sul. Ciência Rural, Santa Maria, v. 39, n. 7, p. 2057-2064, 2009.

TARTARI, D. T.; NUNES, M. C. M.; SANTOS, F. A. S.; FARIA JUNIOR, C. A.; SERAFIM, M. E. Perda de solo e água por erosão hídrica em Argissolo sob diferentes densidades de cobertura vegetal. Revista Brasileira de Agroecologia, Cruz Alta, v. 7, n. 3, p. 85-93, 2012.

VILARINHO, N. K. C.; KOETZ, M.; SCHLICHTING, A. F.; SILVA, M. C. M.; SILVA, E. M. B. Determinação da taxa de infiltração estável de água em solo de cerrado nativo. Revista Brasileira de Agricultura Irrigada. Fortaleza, v. 7, n. 1, p. 17-26, 2013.

ZALUSKI, P.; ANTONELI, V. Variabilidade na Infiltração da Água no Solo em área de Cultivo de Tabaco na Região Centro-Sul do Paraná. Caderno de Geografia, Belo Horizonte, v. 24, n. 41, 2014.

ZHAO, Y.; PANG, H,; WANG, J,; HUO, L.; LI, Y. Effects of straw mulch and buried straw on soil moisture and salinity in relation to sunflower growth and yield. Field Crops Reserch, [S.1.], 2014. http://dx.doi. org/10.1016/j.fcr.2014.02.006.

ZHOU, L.; JIN, S.; LIU, C.; XIONG, Y.; SI, J.; GAN, Y.; LI, F. Ridge-furrow and plastic-mulching tillage enhances maize-soil interactions: Opportunities and challenges in a semiarid agroecosystem. Field Crops Research. [S.1.], v. 126, p. 181-188, 2012. 